\title{
Mecanismos de inserción sociopolítica en Curiepe, Estado Miranda, Venezuela ${ }^{* *}$
}

\author{
Mechanisms of Socio-political Insertion in \\ Curiepe, Miranda State, Venezuela \\ Mecanismos de inserção sócio-política em \\ Curiepe, Estado de Miranda, Venezuela
}

\footnotetext{
* Candidata a Ph.D en Antropología. Laboratorio de Antropología del Desarrollo. Centro de Antropología J.M. Cruxent. Instituto Venezolano de Investigaciones Científicas (IVIC).Correo electrónico: meybyugueto@yahoo.es-mugueto@ivic.gob.ve

** Este artículo de investigación es una versión revisada y ampliada de la ponencia ofrecida en el XXXI Congreso Internacional de la Asociación de Estudios Latinoamericanos - LASA 2013 - ¿Hacia un Nuevo Contrato Social? en Washington, D.C., EE.UU. Agradezco al Laboratorio de Procesos Etnopolíticos y Culturales del Centro de Antropología del IVIC, en la persona de Berta Pérez por brindarme la plataforma institucional para la elaboración de este artículo. Al Fondo Nacional de Ciencia, Tecnología e Innovación (FONACIT) por el financiamiento que permitió mi asistencia al mencionado congreso. A Evelyne Laurent-Perrault y Franklin Perozo por el impulso motivador. A Nuria Martín por la elaboración del mapa incluido en este artículo y a Krisna Ruette y a Hortensia Caballero por su apoyo y excelente orientación académica. Articulo recibido el o7/05/2015y aceptado el 22/07/2015.
} 



\section{Resumen}

Abstract

Resumo

Dado el cambio sociopolítico iniciado en Venezuela en 1999, ¿puede afirmarse que la totalidad de los afrovenezolanos hacen uso de los espacios jurídicos, sociales y políticos derivados de la Constitución para insertarse dentro del proyecto nacional, como sector culturalmente diferenciado de la sociedad? Los logros del movimiento social afrovenezolano son una respuesta favorable, pero no pueden generalizarse aún como una respuesta masiva de la consciencia cultural afrovenezolana. Sin embargo, podemos analizar las realidades locales para dar cuenta históricamente de los procesos sociopolíticos de inserción de estas comunidades. En este trabajo analizamos a la población de Curiepe, del Estado Miranda en Venezuela, desde la antropología interpretativa. Concluimos que su accionar es derivativo de los mecanismos culturales creados dentro de su proyecto de libertad en el siglo XVIII, como pueblo de "negros libres", y su vigencia se expresa estructuralmente en lo que llamamos “autonomía cultural”, sobre todo en el ámbito religioso.

\section{PALABRAS CLAVE:}

Identidad Política | "Negros Libres" | Afrovenezolanos

Considering the socio-political changes initiated in Venezuela since 1999, we ask if all Afro-Venezuelans make use of the legal, social and political spaces derived from the constitution, in order to be included in the national project as a culturally distinct sector of society. The achievements of the Afro-Venezuelan social movement are favorable, but cannot be generalized as a massive response of the Afro-Venezuelan cultural awareness. However, we can analyze local contexts to account for historical processes of sociopolitical inclusion of these communities. This paper analyzes from an anthropological interpretative perspective the case of the population of Curiepe, Miranda State in Venezuela. We conclude that their current socio-political actions derive from cultural mechanisms created since the eighteenth century, based on their project of freedom and on their identity as a "free black" settlement. The validity of these mechanisms is structurally expressed in their sense of "cultural autonomy," especially in the religious sphere.

\section{KEYWORDS:}

Identity Politics | "Free blacks" | Afro-Venezuelans 
Devido à mudança sociopolítica iniciada na Venezuela em 1999, pode-se afirmar que a totalidade dos afro-venezuelanos fazem uso dos espaços jurídicos, sociais e políticos derivados da Constituição para insertar-se dentro do projeto nacional, como setor culturalmente diferenciado da sociedade? As conquistas do movimento social afro-venezuelano são uma resposta favorável, mas não pode generalizar-se ainda como uma resposta massiva da consciência cultural afro-venezuelana. No entanto, podemos analisar as realidades locais para dar conta historicamente dos processos sociopolíticos de inserção destas comunidades. Neste trabalho analisamos a população de Curiepe, do Estado de Miranda na Venezuela, a partir da antropologia interpretativa. Concluímos que sua maneira de agir é derivada dos mecanismos culturais criados dentro de seu projeto de liberdade no século XVIII, como povo de "negros livres", e sua vigência se expressa estruturalmente no que chamamos de "autonomia cultural", principalmente no entorno religioso.

\section{PALAVRAS CHAVES:}

Identidade política | "negros livres”| Afro-venezuelanos 


\section{Introducción}

El 19 de abril de 1703, 23 esclavizados fugados de la Isla de Curazao llegaron a bordo de dos canoas a las costas de Coro en la Provincia de Venezuela; venían tras la promesa de libertad que, a cambio de su conversión a la fe católica, España ofrecía a aquellos fugados de colonias enemigas. ${ }^{1}$

12 años más tarde, en 1715, Juan del Rosario Blanco (JRB) capitán de la Compañía de morenos y zambos libres de las Milicias de Caracas, junto a otros morenos libres del mismo regimiento ${ }^{2}$, dirigió un memorial al Rey Felipe V de España, suplicándole licencia para fundar una población y reunir en un mismo territorio a los morenos libres que se encontraban realengos por la Provincia, a aquellos que no tuviesen sitio propio y a los negros hermanos antillanos (Castillo, 1981a). Petición en concordancia con las disposiciones legales coloniales que emergieron desde muy temprano el siglo XVII en Hispanoamérica, para dar control sociopolítico y económico a la dispersa población de ascendencia africana, en especial la que regía la estructuración étnica-espacial de los territorios de ultramar españoles. ${ }^{3}$

1. Los curazoleños o negros antillanos escapaban de la colonia holandesa por los maltratos y humillaciones a los que eran sometidos y por las "mejoras", en cuanto a su condición como personas, que ofrecía la Corona Española. La libertad a cambio de la conversión religiosa, se reglamentó en varias cédulas y disposiciones: la Real Cédula pronunciada desde Madrid en 1680 al gobernador de la Isla de Trinidad sobre la libertad de los esclavos fugados a las colonias españolas en Tierra Firme (Aizpurua, 2001: 98-99). Otra Real Provisión se emitió el 15 de junio de 1704, a cambio de que se asimilaran a la fe católica, se les ofrecía además un lugar para vivir (Castillo, 1981a: 346). El 24 de septiembre de 1750 se emitió una Real Cédula para declarar en libertad a los negros provenientes de las colonias inglesas u holandesas a los reinos de España que buscaban el agua del santo bautismo (Aizpurua, 2001: 99-100). Y por último: "La Real Cédula proveída por Carlos IV el 14 de abril de 1789 que otorgó la libertad, sin necesidad de pagar rescate, a los esclavos que huían de colonias extranjeras por causa de "malos tratos" (Ponce 1994: 39-40).

2. Proyecto colectivo en el que participaron además de JRB, el alférez Juan de Luis Nieto, el sargento Sebastián de Fuenmayor y los cabos de escuadra Antonio Francisco de la Vea y Pedro de Santa Rosa.

3. Dado el creciente número de descendientes de africanos que adquirían libertad a través de distintas vías (Acosta, 1967; Moscoso, 1995; Ramos, 1943), se dictaron disposiciones para su regulación desde el temprano periodo colonial (siglo XVI), enfocadas a la concentración de la población africana libre en territorios bajo control eclesiástico, civil y/o militar europeo, en estructuras distintas a las llamadas repúblicas de españoles o de indios (Cáceres, 1998). Hubo casos donde la regulación directa fue de la mano de población afrodescendiente, como en Curiepe. Entre 1541 y 1587 se emitieron alrededor de nueve Reales Cédulas que cuestionaron la convivencia de africanos y sus descendientes en pueblos de indios (Cáceres, 1998:3). Las autoridades reales manifestaban un claro rechazo ante la convivencia de este sector de la población con pueblos de españoles; entre los años 1587 y 1589 se promulgaron nuevas disposiciones para regular esta materia (Cáceres, 1998: 3). En el siglo XVII la legislación ya comenzaba a abundar: entre 1605 y 1648 se emitieron al menos diez Reales Cédulas cuestionando la política de residencia que involucraba a indios y a afrodescendientes en un mismo pueblo: en 1608 el Consejo de Indias de Hispanoamérica demandó una solución al Virrey del Perú para enfrentar este problema, y en 1609 el Consejo de Indias los redujo a pueblos de españoles (Cáceres). En 1689 una Real Cédula dirigida al Marqués de Casal, Gobernador de Venezuela, en respuesta a las quejas procuradas por los Capuchinos de las Misiones de Caracas, intentaba controlar a la población cimarrona y libre que se encontraba dispersa, sin estabilidad y sin regulación civil ni eclesiástica, determinando su libertad y "poniendo a éstos en pueblo aparte, tres o cuatro leguas separados de los indios (...) se le forme población separada 
El Gobernador de la Provincia de Caracas, entre 1711 y 1714, José Francisco de Cañas y Merino (Ferry, 1989: 112), acatando la Real Provisión del 15 de junio de 1704 envía a la mencionada Compañía 16 curazoleños huidos quienes buscan su libertad legalmente en Tierra Firme (Castillo, 1981a:348; Ferry). Es probable que estos antillanos sean parte de los 23 que llegaron a Coro en la mencionada fecha de 1703, ya que el grueso de la documentación que el historiador Ramón Aizpurua estudia al respecto forma parte de una legitimación de tierras en Curiepe en 1721, año en que los morenos libres dan por fundado su pueblo4 (Aizpurua, 2001: 76).

En 1720, basándose en la legislación de dar gobierno a la gran cantidad de negros y mulatos libres dispersos en la Provincia, JRB envía un segundo memorial con mejores argumentos ${ }^{5}$ y asume los mandatos reales de: 1) la custodia de la ciudad a través de la lealtad de la Compañía para resguardar las costas de colonias enemigas de España y del contrabando; 2) procurarle sitio a los negros antillanos prófugos de las Colonias Holandesas e Inglesas;3) la solución propia de pagar sus gastos y tributar, a través de sembrar y producir ellos mismos y no estar ociosos y vagabundos por las tierras del Rey; y 4) ya poblados, seguir las condiciones de las autoridades españolas con el nombramiento de justicias y Cabo y la instalación de un curato. ${ }^{6}$

En junio de 1721, en la fiesta de San Juan Bautista y por disposición legal del Auto dictado por el Gobernador de la Provincia de Caracas el Licenciado Antonio José Álvarez Abreu, nace el Pueblo de "Nuestra Señora de Altagracia y San Joseph de la Nueva Sevilla de Curiepe, Cabo de Quadera, Sabana de Oro y Ensenada de Higuerote" (Castillo, 1981a: 380), de la mano de descendientes de africanos en condición de libertad.

En las primeras décadas del siglo XVIII, en la Provincia de Venezuela, y en plena vigencia del régimen esclavista, "negros, morenos, mulatos o zambos" que habían adquirido su libertad, hacían uso de la legislación colonial y de sus contradicciones,

y retirada de la de los indios por los daños que le puede ocasionar su comunicación, pero en entre poblaciones de españoles, tierras adentro y en parte segura, de donde no se pueda recelar alguna invasión o levantamiento." En una Real Cédula de 1702 el Rey atendió lo solicitado, y mandó que valiéndose de los mismos religiosos Capuchinos se redujeran a pueblos a los negros cimarrones y demás gente de esa índole, como mulatos, negros libres, indios y aún españoles, que habitaban en los montes y andaban vagando por todos lados sin oficio ni beneficio. Nada de esto llegó a cumplirse en ese tiempo, y ante los reclamos de Fray Marcelino de San Vicente en 1710, y del Obispo Fray Francisco del Rincón en 1715, la Cédula se sobre encartó en 1716 (Castillo, 1981a: 344-345).

4. El Gobernador Francisco de Cañas y Merino fue uno de los pocos que cumplió la Real Provisión del 15 de junio de 1704, en la que además de conceder libertad a los esclavizados huidos de las Antillas, a cambio de que se asimilaran a la fe católica, ofrecía un lugar para vivir (Aizpurua 2001; Castillo, 1981a; Ferry, 1989).

5. Tales argumentos respondían a los graves problemas de la Corona española para administrar y reducir a los negros y mulatos libres, que se encontraban sin sujeción territorial clara, sin tributar, sin ningún rol concreto para las autoridades españolas y sin control de las autoridades civiles y eclesiásticas.

6. División político-administrativa no formal dada por la autoridad eclesiástica colonial. "Parroquia, territorio que está bajo la jurisdicción espiritual del cura de almas” (Alonso, 1968: 1311). Para el caso de Curiepe, el curato de 1734 constituyó, más que la sobreposición del poder colonial, la posibilidad de consolidarse físicamente en el territorio. 
como andamiaje de su proyecto libertario, y con la intención explícita de insertarse en la estructura organizativa legal de la sociedad colonial, desde la asunción de su condición étnica como principal argumento, pero en iguales condiciones políticas a la población blanca. Se trató de la fundación de un pueblo de características acordes a los existentes para otros grupos étnicos, pero dirigido por población descendiente de africanos, que optaban por una respuesta al sistema esclavista diferente a la huida (Bilby, 2006; Price, 1971), al enfrentamiento bélico (Carrera, 1987), a las peticiones de derechos personales (Dávila, 2009; Laurent-Perrault, 2012) o a cualquier otra forma de resistencia cultural diseñada por los afrodescendientes durante el contexto esclavista.

Este ensayo busca comprender, bajo la luz de estos mecanismos iniciados en 1721, las formas contemporáneas que tienen los curieperos para insertarse en la actual sociedad envolvente. Esto implica comprender la dinámica de los procesos identitarios de esta población; el ámbito que hemos encontrado para su estudio es el religioso, dada la transversalidad que tiene en la vida cotidiana del curiepero.

Estos procesos identitarios fueron analizados a partir de la interrelación de tres íconos religiosos importantes del amplio santoral curiepero actual, los cuales son triangulados en una relación que da cuenta de también tres niveles de interacción de la identidad: el local, el regional y el nacional-internacional. A saber: 1) la relación entre los propios curieperos y el otro afrovenezolano trazada por los eventos asociados a San Juan Congo (SJC); 2) la relación del curiepero y la región centro-norte del país trazada por los eventos asociados al Niño Jesús de Curiepe (NJC); y 3) la relación del curiepero con la sociedad nacional e internacional trazada por los eventos asociados a San Juan Bautista (SJB).

Las formas de inserción dentro de la sociedad actual están siendo acompañadas por el proceso de cambio jurídico iniciado en 1999 en torno a la visibilización legal de la diversidad cultural venezolana, y el cada vez mayor reconocimiento de la población descendiente de africanos en el país; sin embargo, para Curiepe estas formas de inserción social no dependen exclusivamente del cambio jurídico y social, puesto que el auto reconocimiento como población descendiente de africanos, y específicamente como "negros libres", es una bandera que han expresado constantemente, sobre todo dentro del ámbito religioso. Creemos por lo tanto, que el ejercicio de petición de derechos y reivindicaciones por parte de los curieperos desde su conciencia cultural como población "negra" o "afrovenezolana", constituye una derivación de los mecanismos iniciados en el siglo XVIII, los cuales se ven fortalecidos actualmente por las políticas de inclusión dirigidas hacia los sectores afrodescendientes de la República Bolivariana de Venezuela. 


\section{Fundación de pueblos por población negra libre: una forma de resistencia}

Curiepe es una población ubicada en la subregión de Barlovento del estado Miranda, de la República Bolivariana de Venezuela, perteneciente al horizonte cultural afrovenezolano, la cual se erige tras los procesos de creación cultural o etnogénesis, suscitados entre individuos de diferentes grupos étnicos africanos y afrodescendientes en el contexto colonial: negros criollos pertenecientes a la provincia de Venezuela: "negros libres", cimarrones ${ }^{7}$ esclavizados de varias haciendas de la zona ${ }^{8}$; y negros provenientes de otras colonias europeas: cimarrones marítimos (Aizpurua, 2001), específicamente curazoleños provenientes de la colonia holandesa. En este proceso de creación cultural también participaron, aunque con menor cuantía, indígenas tomusas de filiación lingüística caribe, blancos pobres; y blancos canarios después de 1728 (Bermúdez, 1994; Castillo, 1981a; b; Chacón, 1979; Guerra, 1978; 1981). El proceso de etnogénesis que resaltamos es el producto de la trata negrera y la institución mercantil de la esclavitud, en el marco de traída forzada de africanos al continente americano, iniciada por europeos en el siglo XVI.

Curiepe se conoce en la literatura como un pueblo descendiente de "negros libres" sólo en su connotación nominal. La fundación de poblados de estas características fue una estrategia de resistencia cultural ejercida de distintas maneras a lo largo de las Américas. Historiadores y antropólogos, abocados al tema de la resistencia cultural mencionan a la fundación de "pueblos libres" como una respuesta más dentro de una gama amplia de recursos que van desde los suicidios, huelgas de brazos caídos, insurrecciones y rebeliones hasta el cimarronaje. Francisco Moscoso (1995), José Ramos Guédez (2001), Alfredo Chacón (1979), Ramón Aizpurua (2001), Rina Cáceres (1998), Jun Ishibashi (2001), entre otros, refieren que es importante mencionar dichas experiencias como casos particulares, los cuales creemos no son susceptibles de ser estudiados bajo las tradiciones investigativas de la condición de separación, como el cimarronaje, o la condición de sujeción como esclavizados en las plantaciones o similares, dadas las particularidades de la relación de legalidad que estos "negros libres" establecieron con el sistema dominante. Stewart King (2012) destaca el reciente interés por el estudio del rol de las "personas libres de color" o "negros libres" en diversos investigadores del área; en un trabajo enciclopédico, este autor compila casos sobre "negros libres" bajo un amplio criterio que los define como los descendientes de africanos que vivían en condición de libertad, aun durante el régimen esclavista colonial. Hace énfasis además

7. Cimarrones huidos a Birongo o Capaya, dejando de ser perseguidos por concentrarse en Curiepe.

8. Algunos pasaron a ser libres por concentrarse en Curiepe. 
en el rol que jugaron en pro del bienestar de la población afrodescendiente, en especial por las acciones que emprendieron para conseguir la libertad colectiva. ${ }^{9}$

La organización político-social legal que logran constituir JRB y sus compañeros de regimiento en Curiepe, fue el principal modelo de libertad que se llevó a cabo, sin ser una experiencia aislada en el continente: La Puebla de los Pardos, Nueva España, La Gomera, San Vicente de Austria (Cáceres, 1998;2003; 2008), Pueblo de Gracia Real de Santa Teresa de Mosé (Landers, 1999), San Lorenzo de las Minas, San Mateo de Cangrejos (Aizpurua, 2004), en Colombia, Costa Rica, Estados Unidos de Norteamérica, Guatemala, El Salvador, República Dominicana y las Antillas mayores, respectivamente. En Venezuela, además de Curiepe, existen otras experiencias de centros poblados ocupados por población afrodescendiente libre: Tanaguarena, Nueva Londres, Nirgua, Paya, Curimagua (Ramos Guédez, 2001); La Sabana (Altez, 1999); Santa María de la Chapa-Macuquita (Aizpurua, 2004), y San Millán (Ishibashi, 2001). La información sobre estos es variada, en algunos casos con amplio desarrollo histórico y antropológico, y en otros con escasa información o solo su referencia nominal.

El estudio antropológico del caso de Curiepe nos ha permitido someter a evaluación al "pueblo libre" y al "negro libre" como categorías comprensivas de análisis para nuestro país, capaces de evaluar la heterogeneidad al interior de las poblaciones afrovenezolanas, así como la vivencia y asunción también heterogénea del régimen esclavista. Y los distintos mecanismos de inserción sociopolítica llevados a cabo por la población descendiente de africanos en Venezuela, como elemento importante a evaluar, para lo cual Curiepe es un ejemplo de inserción y negociación al y con el sistema dominante envolvente, desde los componentes culturales afrodescendientes.

De este modo planteamos, desde el estudio de caso, que la fundación del "pueblo libre" de Curiepe constituyó una forma de resistencia cultural que se materializó en la construcción explícita de un proyecto sociopolítico colectivo llevado a cabo por descendientes de africanos en condición de libertad, el cual se erigió a través de mecanismos de negociación en los ámbitos religiosos, económicos y políticos, en el contexto de una sociedad asimétrica. Este proyecto fue llevado a cabo de forma consciente y planificada, echando mano de la legislación vigente así como de sus contradicciones; tomando parte de las exigencias y derechos que les planteaba el sistema colonial, a la par de ser conscientes de su condición étnica, para así recuperar, alcanzar y/o mantener la libertad dentro del reinante sistema esclavista, y con el fin de garantizar la existencia y continuidad biológica, territorial y cultural del grupo.

9. Para King, una persona libre de color o un negro libre era: "Someone who had some African ancestors, lived in a colony or independent country in the Americas where slavery existed, but managed to become free for least part of his or her life while other African Americans continued to suffer under slavery. The period covered here is from the voyage of Columbus forward to the beginning of the 2oth Century" (2O12: XV). 
El proyecto que JRB plantea es concebido para descendientes de africanos en distintas condiciones de existencia: esclavizados, cimarrones y sobre todo libres. En el año 1728 , cuando 74 familias canarias pretendieron ocupar las mismas tierras, JRB adelantó acciones para afianzarse en el Valle de Curiepe, y logró que las leyes se inclinaran a su favor. El tejido étnico-social y político de Curiepe era bastante complejo, dada la permeabilidad de integración de otros sectores culturales. Esto puede verse cuando el Obispo Mariano Martí, al pasar por la localidad de Curiepe en 1784, encuentra "99 casas en el pueblo y 55 fuera de él; 2 barrios, Nuestra Señora de Altagracia y Osma..." (Diccionario de Historia de Venezuela, 2010: 1148) con una población de 1.360 habitantes distribuidos de la siguiente forma: 51 blancos, 16 indios, 295 mulatos, 546 negros y 452 esclavizados. Aunque no es explicita la nominación de negros libres en este reconocimiento del Obispo Martí al pasar por el Valle de Curiepe, advertimos que son la mayor parte: 841 afrodescendientes entre mulatos y negros. Efectivamente, en los censos que revisamos de fuentes secundarias (Brito, 1961, 1972; Camacho, 1979; Chacón, 1979; Martí, 1969; Ramos Guédez, 2005; Rojas, 2004), comenzamos a notar la existencia de un reglón de población afrodescendiente en condición de libertad, a veces subsumida en categorías propias de la mezcla de la época (negros, zambos, mulatos, morenos, cuarterones, quinterones, salto atrás, etc. $)^{10}$, pero separada de aquellos clasificados como población esclavizada: por lo cual podríamos inferir que eran negros en condición legal de libertad.

La fundación del "pueblo libre" de Curiepe se diferencia de las heterogéneas y diversas condiciones de existencia que pueden arroparse bajo la tradición cultural del cimarronaje o bajo la condición de sujeción: 1) por el carácter legal, negociado y de inserción al sistema dominante; 2) porque el modelo de resistencia adoptado por los antepasados de los curieperos, aunque llevado a cabo a través de vías monárquicas, se orientó a buscar un espacio de autonomía donde construir y recrear su cultura de matriz africana dentro del marco de la ley.

Para JRB y sus compañeros era necesaria la relación con el Rey como súbditos, para así establecer una especie de "paralelismo" sociopolítico y económico con los blancos; el cual se traducía por un lado en deberes, como el pago de tributo, la aceptación e instauración de la institución eclesiástica, militar y civil dentro del pueblo; y por el otro, la exigencia de derechos a las autoridades provinciales y reales. El floklorista Juan Pablo Sojo habla de "paralelismo" institucional y no de igualación o asimilación, para denotar el equiparamiento que ejercieron los curieperos en el ámbito religioso, noción que extendemos para comprender la que se da en términos sociopolíticos. Esto implicó no sólo construir instituciones equivalentes a las de la sociedad blanca, sino fundamentarlas ideológicamente desde la conciencia étnica, la consciencia de la subordinación 
política que vivían, y a su vez la posibilidad de mejoramiento social tras las hendiduras del propio sistema, para consolidar la libertad más allá de la asimilación y la pérdida de control sobre elementos de la cultura.

\section{La Religión y la inserción sociopolítica: una forma de Identidad}

Este paralelismo cultural del que habla Sojo, manifiesto sobre todo en el ámbito religioso, nos lleva a comprender la actuación de los curieperos en torno a los procesos de inserción sociopolítica que han llevado a cabo dentro de los distintos sistemas políticos surgidos luego del periodo colonial. La relevancia de la religión para el momento de la génesis de Curiepe en 1721 es vital para comprender cómo la identidad política del curiepero contemporáneo se sustenta en la actualización constante de su pasado fundacional como "negros libres", sacralizado en la celebración de San Juan Bautista. Es decir, la libertad colectiva lograda y ritualizada en una ceremonia religiosa, primero impuesta y luego apropiada tras los procesos de etnogénesis, ha permitido a los curieperos insertarse dentro de sucesivos proyectos políticos desde los elementos de cultura propia usando el contexto legal como plataforma, para luego apropiarse y asumir esos espacios desde la autonomía cultural. Las sociedades religiosas, asumen parte de la estructura eclesiástica católica, pero son administradas de acuerdo a los elementos culturales afrodescendientes; los rituales y ceremonias asociadas a estas imágenes se realizan fundamentalmente en las estructuras llamadas veloriosy veladas ${ }^{11}$, peregrinajes ${ }^{12}$, paseos $^{13}$, encierros de santos ${ }^{14} \mathrm{y}$ tambores. ${ }^{15}$ Estas se adosan a los preceptos

11. Los velorios/veladas de santos son espacios de intercambio de bienes simbólicos y tangibles, donde se honra la imagen con expresiones de fe que van desde los rezos netamente católicos como el rosario, hasta expresiones musicales, poéticas y dancísticas que son parte de los elementos recreados del continente africano. Los velorios/ veladas constituyen incluso eventos de prestigio y de popularidad dentro de la sociedad curiepera. Tienen lugar durante la noche (velorios) o durante el día (veladas).

12. Acompañamiento que se hace a una imagen por devoción a un santuario o a tierras diferentes, con acompañamiento musical.

13. Recorrido que se hace con la imagen religiosa por las calles del pueblo, acompañada de música de viento ejecutada por una tradicional escuela de música de Curiepe.

14. Culminación del evento de devoción de una imagen al llevarla al lugar donde permanece custodiada todo el año. En Curiepe, la imagen objeto de "encierro" es la de San Juan Bautista, la cual se lleva a la iglesia luego de la celebración con "tambores" alrededor de las principales calles del pueblo, para luego ser "robada" por la puerta lateral de la iglesia y llevada finalmente a la casa custodia donde permanece todo el año.

15. Se usa la voz: "Los Tambores" para hacer alusión: 1) al evento político y religioso que engloba la celebración a SJB en especial; y 2) para referirse a baterías de instrumentos musicales de tipo percutivo (Brandt, 1987); y 3) para referirse al baile que se ejecuta durante la celebración. 
de la iglesia, pero funcionan paralelas a esta, en una especie de relación conflictiva pero necesaria que impide la ruptura pero que amerita la negociación. Esta curiepera nos muestra esta relación:

"El cura es importante en nuestro cuerpo de creencias y de fe, y el cura tiene un lugar. Yo creo que la disputa con la Iglesia viene por el lugar súper importante que tiene, pero es el que le asignó la población. No es lo que decide Roma. Entonces nosotros asumimos al cura desde nuestro cuerpo de creencias y de fe, desde la cultura curiepera y no desde los preceptos romanos, indudablemente. Entonces eso es lo que hace que haya una controversia siempre" (LCC 16, 2012). ${ }^{16}$

El espacio religioso tiene un sitial fundamental en la vida y consolidación de Curiepe como "pueblo libre": 1) los curieperos asumen los 23, 24 y 25 de junio como un espacio de libertad de los afrodescendientes, puesto que se asocia con la fundación del pueblo el 24 de junio de 1721 (Castillo, 1981a); y 2) Curiepe se estabiliza físicamente a partir de fundación eclesiástica de la parroquia en 1732, dado que su continuidad estaba en riesgo constante por ser un pueblo administrado por descendientes de africanos, y por las querellas que existían en torno a las tierras del Valle entre los sectores blancos de la sociedad. Estos elementos hacían muy frágil la permanencia del "pueblo libre" luego de 1721, por lo cual la instalación del curato fue necesaria para consolidar la estabilidad del poblado. Las autoridades eclesiásticas le asignaban un rango político-administrativo más sólido al pueblo, garantizando que los abusos por parte de la población blanca de la zona al menos disminuyeran. A ejemplo de ello podemos mencionar que los curieperos ya habían experimentado la demolición de sus casas por orden del Gobernador de la Provincia en 1722. Ante lo cual el capitán de los morenos libres reaccionó enviando una petición al Gobernador para que reconsiderara la medida tomada por su despacho, y así resguardar las 16 casas y las dos calles que habían logrado consolidar para entonces. Por su parte, los demás habitantes hacían lo suyo permaneciendo en los alrededores del poblado y en espera de noticias del capitán fundador. Efectivamente, el establecimiento del curato coadyuvó a asegurar la continuidad del Curiepe en el tiempo.

La vida religiosa y el catolicismo pasaron así a formar parte activa de los procesos de reconfiguración cultural en Curiepe, desde su imposición hasta su apropiación.

16. LCC16, 2012 identifica a una persona entrevistada en Curiepe. La combinación de letras y números antes de la coma (,) es la nominación adjudicada a la persona en el trabajo de investigación, para resguardar su identidad; el número colocado luego de la coma hace referencia al año de la entrevista. Este mismo esquema se aplica en las siguientes citas. 


\section{Religión e inserción sociopolítica}

Son tres los íconos sobresalientes del panteón religioso del curiepero de hoy: San Juan Congo (SJC), Niño Jesús de Curiepe (NJC) y San Juan Bautista (SJB), triangulados y relacionados con el pasado fundacional del pueblo y a su vez asumidos como emblema de los curieperos. Esto deriva en una dinámica procesual que permite definir al curiepero en tres niveles por el tipo de relaciones sociales y políticas que se concentran a partir de las imágenes y los eventos en cuestión:1) la relación entre los propios curieperos y el otro afrovenezolano trazada por SJC; 2) la relación del curiepero y la región centro-norte del país trazada por el NJC; y 3) la relación del curiepero con la sociedad nacional e internacional trazada por SJB.

El santo, cualquiera que este sea es por excelencia la instancia simbólica mediadora de los conflictos, alegrías, penas y dificultades en Curiepe; tanto los conflictos dados entre los propios curieperos, como los conflictos suscitados con otros. El ámbito de los otros involucra dimensiones locales, regionales, nacionales e internacionales: los otros son los otros afrodescendientes, los otros barloventeños, los otros mirandinos, los otros venezolanos y los otros extranjeros, en sus distintos roles sociales; diferenciados en las formas de relacionarse con estos y en la forma de establecer las alianzas, entablar los conflictos y proponer las negociaciones, así como diferenciando también cuál de los santos es el destinado para dicha mediación.

Las veladas/velorios, los tambores y el encierro, las peregrinaciones, los paseos, etc., por ser los eventos que celebran a los santos en cuestión y por ser parte del mundo religioso, constituyen los escenarios desde donde se dirimen tales conflictos, desde donde se crean, fortalecen o se rompen los vínculos sociales; también son el espacio desde donde se disfrutan las alegrías y bienaventuranzas individuales y sobre todo las colectivas. Son también para el curiepero un espacio político donde traza relaciones de negociación con los centros y actores que sustentan poder en sus diversas interacciones: horizontales y verticales. La esfera de lo religioso, además de constituir un espacio para la reconstrucción y significación cultural en sí misma, permite trazar relaciones para la definición y afirmación identitaria afrodescendiente del curiepero, anclada en la interpretación de la religión católica impuesta desde los elementos resignificados del continente africano. Es importante destacar que esta esfera de lo religioso no se limita a la estricta devoción hacia el santo o a su imagen, sino que posee un amplio espectro dentro del orden socioestructural del curiepero. Alrededor de las figuras y eventos religiosos se tejen relaciones sociales de otro tipo que la mayoría de las veces depende, emana o se relaciona con el mundo religioso. Actividades deportivas, culturales y políticas se estructuran a partir de, por ejemplo, la Semana Santa, los Tambores, los velorios de santos. 


\section{San Juan Congo: expresión de la identidad local}

SJC es la única imagen que se califica como negra o afrovenezolana dentro de la iconografía sobre San Juan existente en los pueblos pertenecientes al horizonte cultural afrovenezolano. Al igual que la celebración en honor a SJB, tiene como marco el velorio de la imagen el sábado siguiente al 24 de junio: durante toda la noche se toca el tambor y se le baila. Esta celebración no se acompaña del acto litúrgico cristiano, lo que sí es indispensable para SJB.

La imagen de SJC se caracteriza por haber sido un encargo de un ancestro curiepero y por estar esculpida con miembros genitales, es decir, con pene, lo que la ubica, según García, dentro de las figuras religiosas que se encuentran en la República Oriental de Congo, llamadas "Nkisis." (García, 1982) ... Nkisi es una figura pequeña de madera con imagen de hombre, con su falo colgante entre sus piernas (García, 2005: 139).

El hecho volitivo de ser una imagen encargada por afrodescendientes y las distintas versiones acerca de su origen, remiten a los curieperos a significarla como el "santo de los negros" ( $\left.\mathrm{C}_{7}, 2 \mathrm{20} 6\right)$, hecho que la coloca como un icono aglutinador de lo afrovenezolano. SJC se celebra en un sector del pueblo denominado La Capilla, lugar donde se encontraba la vieja iglesia del Curiepe, hecho que permite la integración del pueblo a través sectores geográficos que poseen una especie de identidad dada por la figura religiosa que albergan. ${ }^{17} \mathrm{Al}$ celebrar la festividad de "El Congo" en La Capilla, los curieperos se definen según la relación estrecha o no con las figuras religiosas que honran. Actualmente, las redes al interior del mundo afrodescendiente, en el marco de las políticas de visibilización orientadas por el Estado venezolano, son vigorizadas por SJC, dado que es considerado el "santo de los negros". Antes de la creación de la Sociedad Religiosa de SJC en el año 2009, la administración de los eventos y de la imagen era hecha desde la espontaneidad de los devotos y miembros de la familia custodia, en especial de los curieperos del sector La Capilla según la tradición correspondiente al llamado "conguito". Por otro lado, la relevancia de la imagen a nivel nacional tenía poco impacto, lo cual ha cambiado en el contexto del Movimiento Social Afrovenezolano y las políticas de reconocimiento de la diversidad cultural del país.

Entre otros aspectos, podemos inferir que la reciente creación de la Sociedad de San Juan Congo en Curiepe surge de la necesidad de mediar las actividades emergentes de esta imagen entre la afrovenezolanidad, lo cual permite la integración sociopolítica del pueblo enmarcada en el reconocimiento de la diversidad cultural que el Estado 
abandera. Curiepe posee elementos históricos y fundamentalmente religiosos que lo hacen susceptible de ser reconocido por esta nueva concepción del Estado.

Un ejemplo final del fortalecimiento de las relaciones desde la afrodescendencia mediadas por la figura de SJC, lo constituye la hermandad entre el pueblo de La Sabana y el pueblo de Curiepe, basada en aspectos económicos y por su puesto religiosos. La versión sobre la llegada de la imagen de SJC a Curiepe, que recoge Juan Pablo Sojo Cardozo (1986:168-172), relata la llegada de dos príncipes africanos al vilorio de La Sabana para ser vendidos como esclavizados. Los dos africanos fueron comprados por un hacendado de apellido Blanco, y llevados al pueblo de Curiepe. Uno de estos príncipes, luego de hacerse libre, manda a hacer la imagen de SJC.

\section{El Niño Jesús de Curiepe: expresión de la identidad a nivel regional}

En la zona barloventeña las fiestas en honor al Niño Jesús se enmarcan bajo la estructura del velorio, de la cual se desprenden otras formas festivas/religiosas como las peregrinaciones, procesiones, paseos, misas, fiestas patronales, etc. En los velorios del NJC, a diferencia de los ofrecidos a SJB o a SJC, no hay danzas en homenaje a la imagen; el peregrinaje, que se realiza en el ámbito regional de distintos pueblos, es otra distinción importante.

Entendemos este peregrinaje como la formalización simbólica e institucional de la conexión cultural y religiosa de los pueblos de Barlovento entre sí y la conexión con los pueblos aledaños y con los pueblos pertenecientes a otras divisiones políticas administrativas de Venezuela, demostrando así la existencia de una relación social, afectiva y religiosa a partir de áreas geográficas que comparten un horizonte cultural común y que trascienden la imposición administrativa del Estado-Nación en su división político-territorial. Actualmente la figura del Niño Jesús de Curiepe es una de las pocas con un peregrinaje así en la subregión de Barlovento que recorre la zona norte del Municipio Brión, alcanza el Estado Vargas ${ }^{18} \mathrm{y}$ antiguamente llegaba al Distrito Capital. Es decir, se moviliza por la región Centro-Norte-Costera del país, concentrando los procesos identitarios de los curieperos a nivel regional.

Otro ejemplo de la importancia como marcador regional de la identidad política del Curiepero y las formas de inscribirse en la sociedad, fue la asamblea extraordinaria del 5 de enero de 2007 en la casa de la cultura de Curiepe.

18. Las negociaciones de los curieperos, a través de las instancias religiosas de las cuales forman parte, las diócesis de Guarenas y del Estado Vargas, materializaron nuevamente el recorrido del Niño Jesús por el Estado Vargas, que se había negado por más de 30 años. En 2009, los jóvenes que hacen parte de la directiva de la Sociedad de Nuestra Señora de Altagracia y su Sagrada Familia, mayordomos, niñeros, líderes culturales y comunitarios, lograron convencer a las autoridades eclesiásticas para reanudar el recorrido. 
Dicha asamblea se efectuó mientras se celebraba una de las veladas/velorios del NJC más concurridas del pueblo, para tomar postura acerca de la decisión inconsulta de la alcaldía de la época de construir un relleno sanitario en las cercanías de Curiepe. Para esta fecha, enero 2007, se habían adelantado conversaciones entre los curieperos, no casualmente los días 24, 26, y 27 de junio de 2006, en el contexto de la celebración de los tambores de SJB de ese año. Este ejemplo revela la importancia de los espacios religiosos para la inserción social en términos de reclamos de derechos, dada la capacidad de congregación que poseen.
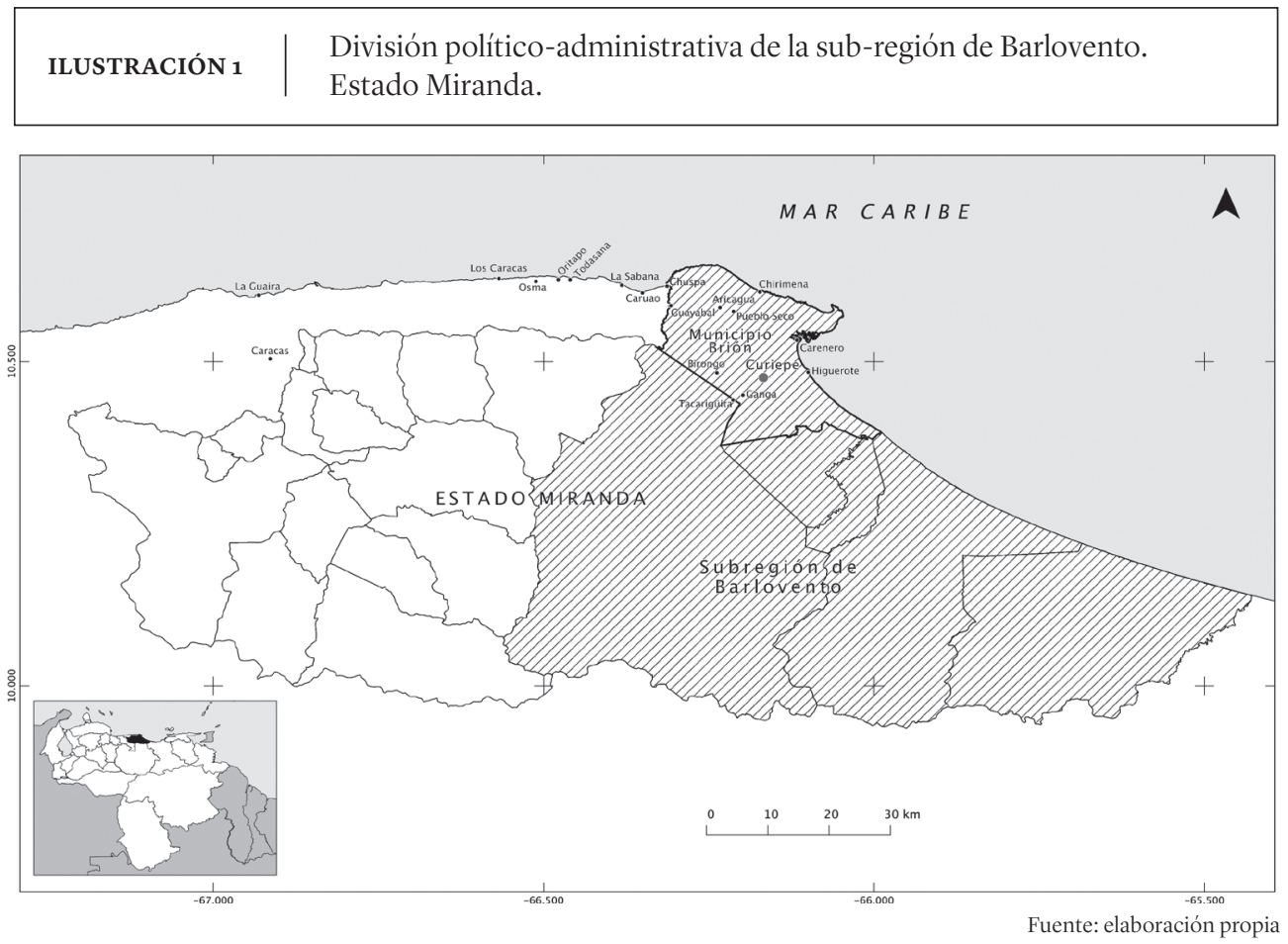

\section{San Juan Bautista: expresión de la identidad a nivel nacional-internacional}

Las celebraciones en honor a SJB se efectúan el día consagrado por la iglesia católica al nacimiento de este profeta, el 24 de junio. En Curiepe se celebran los días 1, 23, 24 y 25 de junio. Como ya mencionamos, en los velorios se rinde homenaje a la mayoría de las imágenes religiosas de Curiepe. La celebración de SJB adquiere mayor envergadura desde 1940, al hacerse visible entre la sociedad nacional e internacional con el festival realizado en la ciudad de Caracas para homenajear la toma de posesión del presidente Rómulo Gallegos (Guss, 2005). 
Otro ejemplo del mecanismo de integración sociopolítica del curiepero a partir del uso de las formas actuales de petición de derechos, lo constituyó lo sucedido en el velorio de SJB del año 2002: se celebró dentro de la Casa de la Cultura del pueblo, empecinadamente y a pesar de las precarias condiciones de habitabilidad, dado los trabajos de remodelación que la gobernación del Estado Miranda realizaba. Los curieperos, como medida de presión y de queja para que las obras se concluyesen, y conscientes del valor turístico nacional e internacional de su fiesta, ese año llevaron la imagen de SJB a su tradicional lugar para velarlo. Un curiepero cuenta que la imagen fue intencionalmente llevada como:

“...el motivo reivindicativo de restauración de la casa de la cultura. Como medida de presión, llevamos a San Juan Bautista a la casa de la cultura, la cual no estaba terminada, ya que en San Juan vienen muchos agentes políticos." (LCC38, 2006).

Para un ejemplo final de los procesos sociopolíticos de inserción mediados por lo religioso y por los procesos de autonomía cultural derivados de la génesis fundacional como "pueblo de negros libres" en Curiepe, veamos la discusión suscitada entre líderes culturales curieperos en torno a las figuras jurídicas de organización comunitaria que el Estado venezolano actual implementa como enlace con las comunidades organizadas.

Los consejos comunales y las organizaciones comunitarias constituyen el esquema de organización del poder popular que se implementa en la Venezuela bolivariana para la asignación de recursos y la toma de decisiones en materia social por parte de las comunidades organizadas. Estas estructuras colindan con organizaciones ya existentes del pueblo de Curiepe, las cuales son fundamentalmente religiosas.

La conversación de un grupo de líderes culturales y comunitarios alrededor de este tema en 2006 ilustra cómo funcionan los mecanismos de autonomía cultural y paralelismo institucional. Estos líderes debatían acerca de seguir organizados, según lo vienen haciendo desde hace ya casi 300 años, bajo la figura de sociedades y hermandades religiosas, sin dejar de ser parte de la lógica organizacional actual del Estado revolucionario, y así insertarse dentro de las nuevas políticas socialistas sin perder autonomía. La posible concentración de todas las organizaciones en una gran cooperativa surgió como alternativa para alcanzar estos objetivos, ya que les permitía mantener la autonomía de cada una de las organizaciones que hacen vida en Curiepe y a la vez insertarse en del modelo de organización sociopolítica actual. La lógica organizacional de las cooperativas dificultaba la concreción de esta propuesta curiepera, en el momento de esta entrevista. Se crearon consejos comunales en varias zonas del pueblo y las sociedades religiosas siguieron funcionando autónoma y paralelamente a estas nuevas formas de organización social. 


\section{Conclusión}

Lo religioso es el escenario de lo político en Curiepe, ya que en sí mismo tiene la capacidad de conglomerar a sus habitantes desde varios ámbitos, en especial el afectivo. Es decir, todos están allí: curieperos que viven en Curiepe, curieperos que viven en Caracas y otros estados del país, autoridades locales, regionales y nacionales, cuyas visitas pueden ser de índole personal o de trabajo, pero se vuelven objeto de reclamos y quejas. El curiepero exige lo que le corresponde por ser parte de la nación; en estas fechas lo hace desde su marcador de identidad afrovenezolana en el contexto religioso. Es decir, tal cual se agenciaban en el siglo XVIII las demandas a las autoridades civiles, eclesiásticas y militares coloniales, como el respeto a las tierras concedidas por el monarca y a las bienhechurías, entre otras, se exige en la actualidad atención en materia de infraestructura, salud, educación, etc. dentro del mismo espacio político de la religiosidad.

En los días ceremoniales, sobre todo los de SJB, acuden turistas al pueblo, y ellos pueden ser la motivación del Estado para cumplir sus obligaciones con el pueblo, pues no es adecuado mostrar al visitante resquicios de inconformidad: el pueblo y la actividad gubernamental se exponen a la mirada de los medios de comunicación y demás actores que atestiguan la desatención.

Los curieperos congregados antes, durante y luego de estas fechas (SJC-NJC-SJB) y alrededor de estas actividades religiosas, se encuentran movilizados y sensibilizados en la reactualización de su tradición, los elementos de identidad emergen y se cohesionan para colectivizar experiencias y afrontar distintos problemas. Los líderes comunitarios y culturales del pueblo comienzan a impulsar los procesos que permiten la discusión, el enfrentamiento, la reflexión, la toma de decisiones, etc., sobre problemas puntuales de la comunidad a partir de su encuentro en los espacios religiosos.

La referencia actual del "proyecto sociopolítico" de "pueblo libre" se expresa estructuralmente como "autonomía cultural" en la toma de decisiones sobre los elementos culturales propios y foráneos que opera fundamentalmente desde el ámbito religioso. Inscrito bajo la lógica de resistencia derivada de los mecanismos culturales creados dentro del "proyecto sociopolítico de libertad" emprendido en el siglo XVIII. Es por ello que sostenemos que la relevancia sociopolítica de los espacios religiosos radica en su operatividad durante los procesos de inserción a la sociedad envolvente, como estrategia de negociación puesta en práctica desde los tiempos coloniales y fundacionales hasta los actuales momentos, llegando a concretar lo religioso como ámbito de ejercicio del poder y eje transversal de la identidad política del curiepero. 


\section{Referencias}

ACOSTA SAIGNES, MIGUEL (1967). Vida de los esclavos negros en Venezuela. Caracas: Hespérides.

AIZPURUA, RAMÓN (2004). "Santa María de la Chiapa y Macuquita: en torno a la aparición de un pueblo de esclavos fugados en Curazao en la Sierra de Coro en el Siglo XVIII". En Boletín NC 345. Sesquicentenario de la Abolición de la Esclavitud en Venezuela (1854-2004). Caracas: UCAB.

(2001). "En Busca de libertad: los esclavos fugados de Curazao a Coro en el Siglo XVIII”. En Influencias africanas en las culturas tradicionales de los países andinos. II Encuentro para la Promoción y Difusión del Patrimonio Folclórico de los Países Andinos. Santa Ana de Coro.

ALONSO, MARTÍN (1968). Enciclopedia del Idioma: Diccionario Histórico y Moderno de la Lengua Española (siglos XII al XX). Etimológico, Tecnológico, Regional e Hispanoamericano. (Tomo I). Madrid: Aguilar

ALTEZ, YARA (1999). “Formación histórica y actualidad de la identidad en La Sabana”. En Boletín Antropológico. Pp. 5-15.

BERMÚDEZ, EDUARDO (1994). Religión, política y etnicidad en la cultura negra en Venezuela. Altos de Pipe: Instituto Venezolano de Investigaciones Científicas I.V.I.C. Centro de Estudios Avanzados.

BILBY, K. M. (2006). True-Born Maroons. Kingston: Ian Randle Publishers.

BRANDT, M. (1987). Estudio etnomusicológo de tres conjuntos de tambores afro-venezolanos de Barlovento. Caracas: C.C.P.Y.T.

BRITO FIGUEROA, FEDERICO (1972). El problema de la tierra y esclavos en la historia de Venezuela. Caracas.

(1961). Las insurrecciones de los esclavos negros en la sociedad colonial. Caracas: Cantaclaro.

CÁCERES, RINA (2008). “La Puebla de los Pardos y las Milicias en Costa Rica”. En Del Olvido a la Memoria: africanosy afromestizos en la historia colonial de Centroamérica. San José, C.R.: Oficina Regional de la UNESCO para Centroamérica y Panamá. 63-77.

(2003) “Negros, mulatos, esclavos y libertos en la Costa Rica del siglo XVII". En Ethnohistory, 50, 758-761.

(1998). "Políticas de control social para negros, mulatos y pardos libres durante el Siglo XVII”. En Dimensión Antropológica,14. 
CAMACHO, ANTONIETA (1979). "Aportes para el estudio de la formación de mano de obra en Venezuela: Esclavos y Libres (1810-1865)”. En Materiales para el estudio de la cuestión agraria en Venezuela (1810-1865). Mano de Obra: legislación y administración. Vol. 1. Caracas: Universidad Central de Venezuela. Facultad de Humanidades y Educación.

CARRERA DAMAS, GERMÁN (1987). “Huida y Enfrentamiento”. En África en América Latina. M.M. Fraginales, ed. México: Siglo XXI / UNESCO.

CASTILLO LARA, LUCAS GUILLERMO (1981a). Apuntes para la historia colonial de Barlovento. Caracas: Academia Nacional de la Historia. (1981b). Curiepe: orígenes históricos. Caracas: Academia Nacional de la Historia. Biblioteca de Autores y Temas Mirandinos. Colección Juan Rodríguez Suárez.

CHACÓN, ALFREDO (1979). Curiepe. Ensayo sobre la realización del sentido en la actividad mágicoreligiosa de un pueblo venezolano. Caracas: Universidad Central de Venezuela/FACES.

CUBA, MARÍA DEL CARMEN (2002). 1. Cultura y poder en la documentación escrita: identidad en los archivos coloniales 2. Análisis de Matalaché. UNMSM.

DÁVILA MENDOZA, DORA (2009). La sociedad esclava en la Provincia de Venezuela, 1790-180o (Solicitudes de libertad-Selección documental). Caracas: Universidad Católica Andrés Bello.

Diccionario de Historia de Venezuela (2010). Curiepe. Caracas: Fundación Polar.

FERRY, ROBERT (1989). The Colonial Elite of Early Caracas. Formation \& Crisis. Los Angeles: University of California Press.

GARCÍA, JESÚS “CHUCHO” (2005). "Presencia africana En Venezuela”. En Ramos, N. (ed.) Resonancias de la Africanidad. Caracas: Fondo Editorial IPASME. 125-142.

(1982) San Juan Bautista y San Juan Congo, reinterpretación y creación de los negros en Venezuela. Caracas: UNESCO. Disponible: http://encontrarte.aporrea.org/pdf. php? $\operatorname{art}=5633 \&$ ej $=21$.

GUERRA, FRANKLIN (1981) Causalidad de las Enfermedades en Birongo: un Análisis del Sistema Conceptual. Centro de Estudios Avanzados. IVIC.

(1978). Birongo. Concepciones mítico-religiosas de un cumbe. $1^{\text {a }}$ aproximación. Volumen III, Universidad Central de Venezuela.

GUSS, DAVID (2005). El Estado Festivo. Raza, Etnicidady Nacionalismo como Representación Cultural. Caracas: Ministerio de la Cultura. CONAC. FUNDEF. 
ISHIBASHI, JUN (2001). “Entierro de la Hamaca de San Millán, Venezuela. Ritual de Autorepresentación cultural y el significado de la violencia”. En Jaramillo de Norden (ed.). Influencias africanas en las culturas tradicionales de los países andinos. Memorias del II Encuentro para la Promoción y Difusión del Patrimonio Folclórico de los Países Andinos. Santa Ana de Coro, Venezuela: Ministerio de Educación Cultura y Deportes, Viceministerio de Cultura, Gobernación del Estado Bolivariano de Falcón, CONAC, Fundación Bigott. 151-166.

KING, STEWART R., (ed.) (2012). Encyclopedia of Free Blacks \& People of Color in the Americas. Volumen I and II. New York: Facts On File.

LANDERS, JANE G. (1999). Black Society in Spanish Florida. Urbana and Chicago: University of Illinois Press.

LAURENT-PERRAUlT, EVELYNE (2012). “El Debate Público de 1@s Afro-descendientes en la Provincia de Caracas, Venezuela.1790-1810”. En Conferencia. Universidad Católica Andrés Bello: Estudios de Postgrado en Historia.

MARTÍ, MARIANO (1969). Documentos relativos a su visita pastoral de la Diócesis de Caracas. 17711784. II. Libro Personal. Caracas: Fuentes para la Historia Colonial de Venezuela. Biblioteca para la Academia Nacional de la Historia.

MOSCOSO, FRANCISCO (1995). "Formas de resistencia de los esclavos en Puerto Rico. Siglos XVI- XVIII”. En América Negra, 10, 31-48.

PONCE, MARIANELA (1994). El Ordenamiento jurídico y el ejercicio del derecho de libertad de los esclavos en la Provincia de Venezuela 1730-1768. Caracas: Biblioteca de la Academia Nacional de la Historia.

PRICE, RICHARD (1971). Marron Societies. New York: Pinguin Books.

RAMOS, ARTHUR (1943). Las Culturas Negras en el Nuevo Mundo. México: Fondo de cultura Económica.

RAMOS GUÉDEZ, JOSÉ MARCIAL (2005). "Mano de Obra Esclava en el Eje Barlovento Valles del Tuy durante el Siglo XVIII”. En Mañongo. 155-167.

(2001). Contribución a la Historia de las Culturas Negras en Venezuela. Caracas: Instituto Municipal de Publicaciones-Alcaldía de Caracas.

ROJAS, REINALDO (2004). La rebelión del negro Miguely otros estudios de africanía. Barquisimeto: Zona Educativa del Estado Lara. Fundación Buría.

SOJO CARDOZO, JUAN PABLO, (ed.) (1986). Estudios del Folklore Venezolano. Los Teques: Biblioteca de Autores y Temas Mirandinos. Instituto Autónomo Biblioteca Nacional y de Servicios de Bibliotecas. 